\title{
Plain Text Data Format
}

National Cancer Institute

\section{Source}

National Cancer Institute. Plain Text Data Format. NCI Thesaurus. Code C85873.

A data format consisting of readable textual material maintained as a sequential file. 